\title{
O (ir)representável da História: o cinema e o arquivo do Holocausto
}

\author{
Miguel Mesquita Duarte*
}

\begin{abstract}
Resumo: Partindo da relação entre o cinema documental do Holocausto e o regime deleuziano da imagem-tempo, este artigo centra-se na análise comparativa de dois filmes, - Shoa, de Lazmann, e Histoire( $s$ ) du cinéma, de Godard, - de forma a compreender diferentes perspetivas sobre a montagem, o audiovisual e o valor das imagens de arquivo como suportes documentais e atos de testemunho.

Palavras-chave: arquivo fílmico; memória; montagem; cinema experimental documental; Gilles Deleuze.
\end{abstract}

Resumen: Partiendo de la relación entre el cine documental del Holocausto y el régimen deleuziano de la imagen-tiempo, este artículo se centra en el análisis comparativo de dos películas -Shoa, de Lazmann, y Histoire(s) du cinéma, de Godard-con el propósito de comprender diferentes perspetivas sobre el montaje, el audiovisual, y el valor de las imágenes de archivo como soportes documentales y como actos de testimonio. Palabras clave: archivo fílmico; memoria; montaje; cine experimental documental; Gilles Deleuze.

\begin{abstract}
Starting from the relationship between the documentary cinema of the Holocaust and the Deleuzian regime of the time-image, this article focuses on the comparative analysis of two films, - Shoa, by Lazmann, and Godard's Histoire(s) $d u$ cinema - in order to understand different perspectives on the montage, the articulation between sound and image, and the value of archival images as documents and acts of testimony.

Keywords: film archive; memory; montage; experimental documentary film; Gilles Deleuze.
\end{abstract}

Résumé: À partir de la relation entre le cinéma documentaire de l'Holocauste et le régime deleuzien de l'image-temps, cet article se concentre sur l'analyse comparative de deux films, - Shoah, de Lanzmann, et Histoire (s) du cinéma, de Godard - afin d'en comprendre les différentes perspectives sur le montage, l'audiovisuel et la valeur des images d'archives comme document et actes de témoignage.

Mots-clés: archives ; mémoire; montage ; documentaire expérimental ; Gilles Deleuze.

\footnotetext{
* Universidade Nova de Lisboa, Faculdade de Ciências Sociais e Humanas Instituto de História da Arte. 1069-061 Lisboa, Portugal. E-mail: miguelfukotomi@ gmail.com

Submissão do artigo: 02 de fevereiro de 2017. Notificação de aceitação: 27 de maio de 2017.
}

Doc On-line, n. 22, setembro de 2017, www.doc.ubi.pt, pp. 216-242. 


\section{Introdução: A imagem-tempo deleuziana e o cinema documental}

Um dos aspetos mais importantes da imagem-tempo deleuziana refere-se à situação ótica e sonora pura. Esta acompanha a emergência daquilo que o autor francês viria a conceptualizar como as formas cristalinas da narração cinematográfica. No novo caminho procurado pelo cinema da imagem-tempo, tudo se passa como num cristal, assistindo-se a uma permanente troca entre a opacidade e a transparência, o visível e o invisível, o presente e o ausente, o verdadeiro e o falso. A imagem é pois empurrada para um regime de coexistência, no qual cada termo não subsiste isolado, mas devém continuamente o seu contrário. Mais exatamente, e seguindo a terminologia deleuziana, o que acontece é que, ao invés de se ligar a ações operativas no espaço, definidoras de um todo narrativo coerente e totalizador, próprio ao regime orgânico do cinema dito clássico (regime da imagem-movimento), a imagem cristalina da situação ótica e sonora pura passa a constituir um circuito de indecidibilidade e de incerteza, pela ligação a uma imagem puramente virtual. O acontecimento narrado pelo cinema envolve agora uma troca recíproca entre o presente e o passado, o verdadeiro e o falso, o atual e o virtual, o real e o imaginário, e o ato do ver é atirado para uma zona de infinita reserva e questionamento.

Por outro lado, perante o critério de coexistência e de indiscernibilidade das imagens cristalinas, que definem o regime da imagem-tempo, não bastava já, para Deleuze, evocar o flashback. Este depende ainda da intervenção de uma consciência individual que restitui o acontecimento narrado através de imagens-lembrança datáveis e perfeitamente determinadas. Aí, o passado surge ainda simplificado como presente antigo, inserido num esquema diegético tendente a explicar a ordem dos factos, por recurso a esquemas de sucessão do antes e do depois. Com efeito, é de notar que, em Deleuze, o critério do cristalino (que deve ser preservado como metáfora de uma condição não-orgânica e mineralizante) não é atribuível à produção subjetiva da mente. Trata-se, pelo contrário, de uma característica inerente às próprias imagens e linguagem cinematográfica, cuja potencialidade é a de fundar uma representação incomensurável das coordenadas de espaço-tempo. Como referia Deleuze, aquilo que nós vemos no cristal não é a progressão empírica do tempo, mas a sua apresentação direta, o desdobramento constitutivo que emerge da interrupção dos prolongamentos racionais e motrizes, confrontando a perceção atual com uma repentina e perturbadora incapacidade de evocação de um passado delimitável.

A imagem-tempo pode por isso ser equiparada, como viu D.N. Rodowick, a uma imagem da memória. Esta envolve uma operação na qual a perceção é continuamente redobrada por uma lembrança, mas uma lembrança que respeita ao constante jogo de reciprocidade entre o presente e o passado. Tudo 
se passa, efetivamente, como numa interminável fita de Moebius. Ora, o que a imagem-direta do tempo apresenta é, justamente, este movimento da própria memória e do pensamento, e não o movimento mecânico dos corpos no espaço. Como escreve Rodowick, "Estas imagens desdobram-se através de deslocamentos na memória mais do que em ligações cronológicas; o espaço é organizado através de uma lógica de falsa continuidade, apresentando o tempo como movimento aberrante" (Rodowick, 1997: 113). Reside aqui a marca da especificidade do cronosigno da imagem-tempo. O cronosigno implica um passado que não pode ser mostrado, ou melhor, um passado que não pode ser identificado e designado nem em função de estados de coisas fixados, nem em função de proposições verdadeiras e totalizadoras. Trata-se de um passado incerto, sem ponto fixo, apontando para séries de desdobramentos e bifurcações nunca completas, até porque o critério da indiscernibilidade aponta para um processo de contínua renovação e reprodução do acontecimento. Como escreve Deleuze, na imagem-tempo:

[...] não há mais ligação entre imagens associadas, mas apenas rearticulação de imagens independentes. Em vez de uma imagem depois da outra, existe uma imagem 'mais' outra imagem, e cada plano é desenquadrado em relação ao desenquadramento do plano seguinte... [A imagem-tempo] põe o pensamento em contacto com o impensável, o inapreensível, o inexplicável, o indecidível, o incomensurável. $\mathrm{O}$ fora ou o reverso das imagens substituiu o todo, ao mesmo tempo que o intervalo ['interstice'] ou o corte substituiu a associação. (Deleuze. Cit. Rodowick, 1997: 14).

Neste sentido, a imagem-lembrança terá, por si só, pouco interesse, enquanto ela não supuser regiões virtuais do passado e ligações que subsistem num constante esforço de evocação, envolvendo a contração do presente como parcela mais vasta de uma procura constantemente redobrada e retomada. Desta forma, várias possibilidades do passado coexistem ao nível de uma arquitetura da memória sem centro fixo ou identificável. É esta relação da imagem-tempo com o fenómeno dos deslocamentos da memória não subjetiva, e consequente aproximação ao sentido próprio de historicidade, tomada enquanto relação de tempos heterogéneos que se encaixam através de múltiplas combinações, que justifica, como pretendemos demonstrar a partir de diferentes exemplos, o encontro entre a teoria de Deleuze sobre o cinema e o filme documental, nomeadamente no momento em que este procura expressar o irrepresentável de um acontecimento limite como o Holocausto. Interessa igualmente pensar a radical transformação da linguagem cinematográfica na sua potência documental e histórica, pois só essa transformação se revelará adequada à narração dos eventos-limite da História. 
Neste sentido, a afirmação de Adorno de que "nenhuma palavra com um tom elevado, nem mesmo uma palavra teológica, permanece com um direito não-transformado depois de Auschwitz" (Adorno 2009: 304), adquire toda a relevância. Esta afirmação, frequentemente citada e ligada, como assinalou Anton Kaes, a um "sentimento de pós-história"(Kaes, 1992, 207), expressa a ideia de que o acontecimento traumático do genocídio perpetrado pelos $\mathrm{Na}$ zis exige uma transformação radical das formas artísticas e do pensamento, as quais devem integrar novas metodologias e configurações, capazes de responderem aos efeitos produzidos pelo Holocausto e pela Segunda Grande Guerra. É esta exigência de transformação radical do cinema, considerada nas suas implicações antropológicas, culturais, filosóficas e políticas, que marca a teoria de Deleuze, algo que, de resto, orienta decisivamente a identificação da passagem que nos leva da imagem-movimento à imagem-tempo. Também aqui, a teoria de Deleuze converge com a problemática do cinema documental enquanto forma alternativa de conhecimento histórico, interessando examinar as transformações formais e semânticas que afetam a linguagem cinematográfica como documento do real.

É o que acontece no exemplo, central na teoria deleuziana, da obra de Alain Resnais. Em Alain Resnais, o inconcebível da morte e da violência do acontecimento produz o apagamento de um centro, ou ponto fixo, a partir do qual aquele poderia ser atingido como instância unitária e conclusiva. Veja-se Hiroshima, mon amour (1959), paradigmaticamente situado num espaço de permanente indecisão entre o documental e o ficcional. O passado não é suscetível de ser estabilizado num ponto fixo e rigorosamente evocável, possibilitador de uma ligação direta com o presente. O diálogo que pontua o prelúdio do filme marca esse caráter de incerteza: "Ele: Tu não viste nada em Hiroshima. Nada. Ela: Eu vi tudo. Tudo". Os planos aproximados dos corpos dos amantes são então intercalados com fragmentos de filmes de arquivo da tragédia de Hiroshima, evocando os limites impossíveis do nada e do tudo daquilo que pode ser dito e mostrado. Esses fragmentos envolvem os afetos e as sensibilidades das personagens numa memória que, todavia, não pode ser reduzida a uma produção subjetiva. Algo de semelhante acontece no documentário de Resnais sobre os campos de concentração e de extermínio Nazi, Nuit et brouillard (1955): "9 milhões de mortos obcecam esta paisagem", apelando a um ponto procurado que é inacessível, um ponto do passado que é da ordem do impensável, não sendo por isso suscetível de atualizar-se numa lembrança totalizadora e unívoca (Deleuze, 2006: 162).

É que, como refere Deleuze, a morte não pode fixar-se no presente como centro determinável enquanto o impensável obscurecer a memória e os níveis 
do passado. Estes envolvem não só a lembrança, mas também "o esquecimento, a falsa lembrança, a imaginação, o projeto, o julgamento..." (Deleuze, 2006:152-53), impedindo que o passado se degrade numa lembrança cronológica balizada pelo modelo do verdadeiro e pelos esquemas interpretativos da história. Desta forma, é a própria narrativa que se vai transformando a partir de vários tempos coexistentes, persistentemente bifurcados e entrecortados, dando azo ao irromper de múltiplas saídas que não são nunca inteiramente concretizadas. Perante o impensável da morte e da destruição, o evento perde a sua invariabilidade e não pára de se transformar e de se recriar como ato de fabulação, como ato de pensamento irredutível à conformação a um modelo de verdade e de universalidade. A verdade não tem de ser produzida ou alcançada. Ela terá de ser criada e fabulada. Desta forma, Deleuze remete-nos para a ideia de uma "função fabuladora" do cinema que, sendo encontrada pelo autor francês no cinema documental de realizadores como Perrault e Jean Rouch, produz a erosão da ficção a favor de uma memória ativa e politicamente comprometida. Porque o que se opõe à ficção não é o real, não é a verdade - cujo modelo, como afirma Deleuze, "é sempre a dos mestres ou dos colonizadores" (Deleuze, 2006: 195), mas a potência de fabulação que inscreve a memória como duração e ato criador de narração.

Isto não significa, como tal, que o acontecimento histórico não possa ser conhecido, interpretado e construído pelas formas do cinema documental, inseparáveis de um certo valor de veracidade que importa preservar ao nível do relato do acontecimento. Simplesmente, história e memória não serão mais apreendidas como facto já dado, cingidas a um único tempo e a um único espaço, devendo ser, precisamente, construídas e reinventadas no seio de um processo imaginativo que une o testemunho e o literário, trazendo consigo uma forma alternativa de construção documental. No cinema documental da imagem-tempo, a história emergirá, mais exatamente, como facto da memória que faz existir aquilo que não pode ser mostrado e que subsiste como pura virtualidade e reserva. Como indicámos, esta questão revela-se crucial no que toca a perspetivar a possibilidade de construção da imagem histórica no momento em que o presente procura contactar com um passado que é atravessado pela dimensão do impensável e do inimaginável, tal como acontece quando consideramos um acontecimento limite como o extermínio na Segunda Grande Guerra. É esta questão que procuraremos abordar nos próximos pontos.

\section{O sonoro e o visual: Shoah e Nuit et brouillard}

Coloca-se uma primeira questão: revelar-se-á adequado suscitar a categoria do inimaginável para os eventos-limite da História? Em Imagens apesar 
de tudo, Georges Didi-Huberman propõe que o inimaginável não deve sequer ser convocado perante as imagens e as palavras que nos chegam das experiências hediondas dos campos de concentração e de morte (Didi-Huberman, 2012: 15). O que está em causa na tentativa de imaginar aquilo que julgávamos impossível é uma dívida e um tributo para com aqueles que se dispõem a relatar essa experiência. Equivale a disponibilizarmo-nos a ver e a ouvir os testemunhos que procuram dar uma forma ao inimaginável, de modo a retirar algo, nesse gesto de humanidade, da vivência de um inferno mecanizado e erigido sob a racionalização do horror. Não é a dimensão hedionda do extermínio de massa que constitui a exclusividade do Holocausto, mas sim o programa industrializado da morte e da supressão, por sua vez acompanhado de um programa de supressão das provas desse ato duplamente monstruoso. Aqueles capazes de testemunhar eram liquidados, e se alguma informação, ou alguém, escapasse para o exterior, os relatos seriam demasiado dispersos, e, sobretudo, demasiado inconcebíveis, como observou Jacques Rancière, para serem inteiramente críveis: ainda que um de vós fique para testemunhar, ninguém o acreditará (Rancière, 2011: 170).

É este o cerne da supressão ligada à terrível lógica negacionista dos Nazis. É esta a maquinaria da desimaginação em que estava sustentada a Solução Final: fazer desparecer os utensílios, as estruturas e as fábricas de liquidação, mas também os arquivos e a "memória do desaparecimento" - forma de "manter, ainda e sempre [o acontecimento] na sua condição inimaginável" (DidiHuberman, 2012: 37). Esta ideia é igualmente defendida por Peter Haidu no seu ensaio The Dialectics of unspeakability (Haidu, 1992). Segundo o autor, nós devemos hesitar profundamente perante a utilização de conceitos como os de irrepresentabilidade e de indizidibilidade para caracterizar o Holocausto. Isso equivaleria a aceitar, e até a perpetuar, depois dos factos e depois das mortes, a apologia do encobrimento e do silenciamento.

É por isso que, para Jacques Rancière, aquilo que se exige representar do Holocausto é "uma dupla supressão: a supressão dos judeus e a supressão das marcas da sua supressão" (Rancière, 2011: 168). A habitual lógica ficcional que aspira ao modelo do todo e do verdadeiro não se coaduna a esta exigência. O inominável do Holocausto é incompatível com o tratamento ficcional, regulado pelos habituais artifícios dramatúrgicos e pela encenação da história dos carrascos e das vítimas numa lógica de espetáculo e distração (Rancière, 2011: 169). Mas também o testemunho puro, pretensamente capaz de restituir factualmente o acontecimento do passado, constitui uma resposta insuficiente, dado que falha a representação da segunda supressão, aquela respeitante ao programa de apagamento das marcas e da memória do extermínio. Dar 
conta dessa dupla supressão metodicamente elaborada exige que se edifique um trabalho de fabulação que incorpora a dimensão lacunar e fragmentária do evento. Implica que a palavra proferida pelas testemunhas seja relacionada com a realidade material e o esvaziamento do lugar onde ocorreu o massacre e o aniquilamento (Rancière, 2011: 168). E, dessa forma, é também a inserção do próprio sujeito-testemunho numa narrativa capaz de atingir o outro, o outro que não experienciou o horror do acontecimento senão indiretamente, que é atingida.

É esta, com efeito, a fórmula ativada por Claude Lanzmann em Shoah, filme-documentário de 1985 que se baseia na coleção dos testemunhos diretos dos sobreviventes do extermínio. As questões colocadas diretamente por Lanzmann aos sobreviventes dos campos solicitam uma resposta, uma descrição do inimaginável. Em Shoa, o conteúdo dos relatos é pontuado pela gravidade dos rostos daqueles que falam, mas também pelas imagens dos lugares agora desertos e esvaziados da presença. Aquilo que é narrado pelo ato da palavra, e que se reporta aos acontecimentos vividos, prolonga-se através da imagem que mostra os vestígios e os lugares esvaziados. Neste sentido, a imagem aparece como testemunho visual e fabulador daquilo que persiste no tempo como rastro e invisibilidade, como ruína do que é descoberto pelos lentos movimentos de câmara. Mas, por esse mesmo motivo, a articulação entre voz e imagem está sempre em falta. Existe uma inadequação entre palavra e imagem, entre discurso proferido na primeira pessoa, que procura desenterrar o episódio no seu terror, e o lugar agora vazio, apresentando-se como clareira, como esvaziamento. É essa inadequação entre sonoro e visual que a montagem sublinha, convocando um ato de construção como imaginação.

Em Shoah, a relação entre a palavra e a imagem implica, assim, aquilo que D.N. Rodowick viria a conceber como um ato de "imaginação histórica". Um ato que nos coloca em contacto com a memória enquanto trabalho de reconstrução e montagem, enquanto "relação histórica" que combina os traços visuais do presente com o ato de testemunho dos sobreviventes (Rodowick, 1997: 147). A palavra que se forma e se torna palpável no lugar esvaziado, adquire, ao ser proferida no presente, uma dimensão alucinatória. O seu real é o real da desaparição, é o momento paradoxal em que a ausência é tornada presente e presença, podendo ser atingida apenas como ato de fabulação, isto é, ato de imagem e de imaginação.

Na primeira sequência de Shoah, por exemplo, Lanzmann acompanha a história de um sobrevivente que revisita o campo de extermínio de Chelmno, na Polónia. O campo encontra-se agora totalmente soterrado na paisagem. A câmara percorre um espaço de grande extensão, mas no qual é apenas possível 
ver uma grande clareira, rodeada de uma densa cortina de árvores que se prolonga indefinidamente. As palavras proferidas pelo sobrevivente, que procura descrever aquilo que ali se tinha passado, formam-se como que estratigraficamente no espaço deserto. A dada altura, e por via da abertura do plano, a presença do corpo é miniaturizada, ocupando uma imagem que aviva o cerne da supressão e a lógica do negacionismo Nazi (Rancière, 2011). Na realidade, é a própria imagem que adquire, na sua relação com o sonoro, uma dimensão estratigráfica. É que aquilo que estava soterrado na paisagem é tornado agora visível através da palavra, que se converte numa imagem independente. A imagem, por sua vez, torna-se legível, adquire um caráter problemático e arqueológico, fazendo surgir múltiplas linhas de confronto entre a imagem visual e a imagem sonora. Esta imagem legível implica, assim - tal como observado por D.N. Rodowick, a partir do que Deleuze considerava como constituindo o regime verdadeiramente audiovisual do cinema (Deleuze, 2006 : 293) - um ato de leitura e de atenção pelo espectador. Este relaciona os dados apresentados através de formas de inteligibilidade que dependem de um registo simultaneamente factual e imaginativo. Só assim o espectador pode imaginar e chegar perto do inominável e do irrepresentável que lhe é apresentado.

A rutura sensorial motriz que funda a narração cristalina da imagem-tempo encontra, desta forma, o seu culminar na apreensão do intolerável que suscita a desarticulação entre o ato da palavra e o ato da imagem. A imagem torna-se ato fundador e faz subir aquilo que está antes e depois da palavra, enquanto esta atinge o seu limite pelo modo como profere o invisível e o inominável do passado do acontecimento. A circulação entre a palavra e a imagem depende de um espaço estratigráfico, apontando para uma zona de exterioridade infinitamente longínqua, dado que o mundo exterior registado encontra-se ocultado, dissolvido no tempo, constituindo um fora, ou um puramente virtual, que força a sensibilidade e obriga a pensar o impensável. Por isso mesmo, o fora remete simultaneamente para um dentro que surge como o impensado no pensamento, uma estranha forma de subjetividade que é mais profunda do que qualquer mundo interior. Em suma, uma subjetividade que se forma num espaço de dramaturgia singular, afeta ao registo documental cinematográfico como exercício fabulatório e operação audiovisual (Deleuze 2006: 354). Esta dissociação entre o sonoro e o visual acaba por fornecer a cada uma das componentes da imagem uma potência renovada, apontando para as múltiplas camadas de significação que organizam o espaço da imagem como algo a decifrar, como ponto enigmático que requer um ato de interpretação ativa. Um ato de pensamento que procura no discurso aquilo que não pode ser visto, e no visível aquilo que a palavra não consegue mais expressar (Rodowick, 1997: 151). 
Este tipo de correlação entre palavra e imagem caracteriza alguns dos mais importantes momentos de Shoah. Todavia, esta marca da audiovisualidade não é algo de exclusivo, nem muito menos de inaugurado, por Claude Lanzmann. No contexto do tratamento do Holocausto pelos meios fílmicos, essa relação encontrava-se já exemplarmente trabalhada por Alain Resnais, embora de uma outra forma, em Nuit et brouillard, de 1955, com textos de Jean Cayrol. Neste caso, o ato da palavra não é o do testemunho direto e na primeira pessoa, correspondendo antes à voz off que evoca, que comenta e que abre a sequência de imagens a uma nova potência sensorial e cognitiva, fornecendo ao não-visto uma presença específica. O discurso autonomiza-se, ultrapassa a imagem visual. Mas sem renunciar a essa imagem completamente, dado encontrar nos lugares desconectados e vazios, que só a câmara pode percorrer, o espaço privilegiado de acolhimento de um ato da palavra que funciona verdadeiramente como testemunho. Por outro lado, a voz off sofre, também ela, um deslocamento, pois deixa de ver tudo de forma omnisciente. Torna-se incerta, questionadora, dado que aquilo de que ela fala é o inominável. Na realidade, já não há fora de campo ou voz off, como observava Deleuze, dado que o fora e o invisível se tornaram a própria imagem visual e sonora, o visual e o sonoro relacionando-se através de um corte irracional, um ponto irracional que faz intervir o pensamento como ato de criação e de construção. Em Nuit et brouillard, este movimento recíproco entre o visual e o sonoro pode ser encontrado, por exemplo, numa sequência em que o travelling faz avançar a câmara sobre os carris que levam à entrada do campo de morte, justapondo-se ao discurso que diz:

Hoje, nos mesmos caminhos, o sol brilha. Percorremo-los lentamente, mas à procura de quê? Do traço dos cadáveres que tombavam no chão quando as portas das carruagens se abriam? Ou talvez daqueles guiados para os campos com uma arma apontada à cabeça, entre o ladrar dos cães e as luzes dos projetores, com o fumo do crematório à distância, numa dessas cenas noturnas tão ao gosto dos Nazis? (Cayrol, 1955).

Mais à frente, sobrepondo-se a um travelling sobre as camas amontoadas dos dormitórios: "[...] nenhuma descrição, nenhuma imagem pode revelar a sua verdadeira dimensão: interminável, ininterrupto medo [...] [Estas imagens] são tudo o que nos resta para imaginar uma noite de gritos penetrantes, de controlo de infestações, de ranger de dentes. É necessário tentar adormecer rapidamente" (Cayrol, 1955). Em Resnais, a palavra cria o acontecimento, e o acontecimento é recoberto pela terra, pela paisagem que oculta os cadáveres, fornecendo um sentido estratigráfico à imagem que complementa a palavra. O sonoro renuncia agora ao exercício empírico de ligações visuais convencionadas, orientando a imagem visual para o limite do invisível e do indescrití- 
vel: nenhuma imagem pode revelar a verdadeira dimensão do acontecimento, como é afirmado em Nuit et brouillard, mas é por ela, ou melhor, é por via da sua relação assíncrona com o sonoro, que é possível imaginar, chegar perto do ponto do inominável e do invisível de uma experiência que não é a nossa.

Uma vez mais, a imagem não regista o espaço nas suas relações mensuráveis, mas imprime o tempo, incorporando a memória e o pensamento do fora no dentro da imagem e da perceção. Como escrevia Deleuze, "a imagem visual nunca mostrará o que a imagem sonora enuncia" (Deleuze, 2006: 355). Cada uma atinge o limite que a separa da outra, descobrindo um território comum de relações incomensuráveis

Desde então, nenhuma das duas faculdades se eleva ao exercício superior sem atingir o limite que a separa da outra, mas referindo-se à outra separandoa. O que a palavra profere é igualmente o invisível como a vista só vê pela vidência e o que a vista vê é o que a palavra profere do indizível. (Deleuze, 2006: 332).

\section{3. $O$ arquivo de imagens: uma imagem sem imaginação?}

O filme Shoah constitui um exemplo incontornável na problemática referente aos limites representativos do cinema. Mas que limites são esses? Ou melhor, quais os limites a que o filme deve obedecer quando está em causa a transmissão de um evento-limite que escapa às habituais metodologias e formas de conceptualização? Para Lanzmann esses limites são claros e dizem respeito à desclassificação das imagens de horror dos arquivos fílmicos. Porém, como notou por exemplo Jacques Rancière, esta posição resulta numa colagem a um discurso ligado ao irrepresentável e ao interdito da representação, e, mais exatamente, ao interdito da imagem.

Não tanto por aquilo que é o filme de Lanzmann considerado isoladamente, pois esse, como se viu, parte de uma utilização da imagem no seu confronto com o ato da palavra, atingindo o cerne de uma experiência representativa e fabulatória. Mas sim porque é o próprio Lanzmann que, em inúmeros discursos e entrevistas, questiona a efetividade da imagem como ato de testemunho, concedendo ao ato da palavra um quase total privilégio, com subsequente menorização dos poderes da imagem. O que está aqui em causa é, igualmente, a problemática relativa aos valores e usos do arquivo de imagens, nomeadamente quando este pode intervir na compreensão e transmissão de um acontecimento decisivo na história do Séc.XX Ocidental. É pois sobre este conjunto de questões que importa refletir.

Lanzmann não podia ser mais perentório quando afirma que a imagem não é capaz de mostrar o indizível e o inconcebível do Holocausto. A imagem não 
mostra tudo - não há, por exemplo, imagens daquilo que se passou no interior das câmaras de gás; não há sequer uma única imagem de Chelmno nem de outros campos de extermínio. Mas mesmo que essas imagens existissem, elas seriam, na opinião de Lanzmann, profundamente insuficientes, dado produzirem uma visão sempre dispersa e incompleta da realidade. Mais ainda, a imagem é, segundo Lanzmann, sem imaginação, pois ela tende a produzir uma ficção do acontecimento; ela tende a estabilizar o horror num ícone espectacularizado, que nada nos diz sobre a experiência do medo e da angústia das vítimas. A imagem de arquivo seria, por isso, um ícone vazio, uma instância que pouco ou nada conta para o verdadeiro conhecimento dos acontecimentos mais extremos. Repare-se nesta passagem de Lanzmann:

Sempre disse que as imagens de arquivo são imagens sem imaginação. Elas petrificam o pensamento e matam todo o poder de evocação. Vale bem mais fazer o que eu fiz, um imenso trabalho de elaboração, de criação da memória do acontecimento. O meu filme é um monumento que faz parte daquilo que monumentaliza, como diz Gérard Wajcman [...] Preferir o arquivo às palavras das testemunhas, como se aquele pudesse mais do que estas, é reconduzir sub-repticiamente esta desqualificação da palavra humana na sua destinação para a verdade. (Lanzmann, $2001: 274$ ).

$\mathrm{O}$ primeiro ponto importante a assinalar neste posicionamento refere-se ao facto de Lanzmann conferir um privilégio absoluto ao ato da palavra. O relato direto e na primeira pessoa dos sobreviventes é, segundo o realizador, o único testemunho passível de nos dar conta da experiência dos campos. É o ato da palavra, e a presença que ganha corpo naquele que a profere, que constitui a única forma adequada de testemunhar a experiência do Holocausto, pois só através da palavra é possível conhecer e imaginar o impossível desse acontecimento. Donde o interesse de Lanzmann pelo pormenor e pelo detalhe dos relatos; as questões por ele colocadas procuram insistentemente ir ao encontro do mais ínfimo e aparentemente banal pormenor das descrições. Lanzmann não se dirige às grandes questões metafísicas sobre o mal, a injustiça ou a redenção. À semelhança do método historiográfico de Raul Hilberg, assumido pelo próprio Lanzmann como a sua grande referência metodológica, Lanzmann procura investigar as pequenas questões: Estava frio?; Desenterrava os corpos com as mãos ou com instrumentos?; Mostre-nos como cortava os cabelos das mulheres... Dessa forma, ele procura retirar dos relatos uma forma de descrição e de construção tão metódica quanto os métodos e os processos usados pelo programa Nazi (Salles, 2012). É dessa descrição cumulativa, que fala, por exemplo, da limpeza dos espaços de onde haviam sido retirados os cadáveres, ou dos preparativos dos corpos para a entrada nas câmaras de gás, - que se levanta o horror do extermínio. Aquilo que emerge é, assim, 
uma imagem como construção, uma imagem que não se converte num cliché, num ícone visual ostensivo e inserido numa forma de ritualização mediática, tendente a transformar o singular e a reserva do Holocausto em informação e objeto cultural. No final, Lanzmann restringe à palavra a faculdade e a força de mostrar o irrepresentável. Mas fá-lo à custa de uma crítica e de uma generalização abusiva da imagem e do arquivo. Como se a imagem de arquivo fosse sempre um mero documento, como se a imagem fosse sempre a mesma, como se ela não dependesse do uso e das formas de montagem em que se insere, das relações originais entre o sonoro e o visual a que dá acesso. Como se a imagem pudesse ser reduzida a uma apreensão consensual e estabilizada do real, aprisionando o acontecimento num ícone de horror que teria como função encobrir e velar, numa forma mais ou menos tranquilizadora, aquilo que é da ordem do irrepresentável.

Shoah é efetivamente caracterizado pelo rigor de uma escolha que prescinde das imagens de arquivo do Holocausto a favor do testemunho dos sobreviventes, produzindo uma obra exímia no seu detalhe e precisão. Tudo se complica, porém, quando essa escolha e esse método é elevado ao valor de uma regra que deve ser obrigatoriamente aplicada em qualquer abordagem séria do acontecimento. Shoah adquiriu, em alguns círculos, uma aura de exclusividade. Transformou-se, para muitos, na única obra sobre o Holocausto. Converteu-se no filme que, ao longo das suas mais de 9 horas de duração, nos dá a verdade toda e única da experiência do extermínio. ${ }^{1}$

Este tipo de posicionamento não se revela frutífero, desde logo, para pensar as potencialidades inerentes ao relacionamento da imagem de arquivo com o testemunho fílmico, falhando a compreensão das especificidades fenomeno-

1. Este tipo de dedução esquemática levanta, obviamente, questões de várias ordens. Somos levados a questionar, desde logo, se uma boa parte da eficácia da estratégia de Lanzmann não depende do facto do espectador já conhecer as imagens de horror do Holocausto e poder imaginar, a partir daí, o terror vivido pelas vítimas. Depois, há a questão do consenso gerado em torno da obra de Lanzmann, que passa para o exterior como se fosse a única representação possível do Holocausto, ignorando-se as influências de filmes como Nuit et brouillard, de Alain Resnais, mas também de Le chagrin et la pitié (1969), de Marcel Ophuls, ambos filmes que recorrem às imagens de arquivo (embora no caso de Ophuls não estejam em causa as imagens de horror dos campos dado que a sua investigação se centra nas razões políticas e ideológicas da colaboração do governo de Vichy com os Nazis). A esses filmes Lanzmann vai buscar o método de combinação entre o discurso e os espaços vazios, no caso do primeiro, e o método da entrevista e do testemunho direto dos sobreviventes, no caso do segundo. Ignora-se, por outro lado, o facto de Shoah não ser, como seria de esperar, um filme que mostra a totalidade da experiência do Holocausto, e, sobretudo, que o filme sofre dos limites e do parcialismo que é comum a qualquer tipo de filme, documental ou ficcional - basta, para isso, lembrar que são as perguntas de Lanzmann que, para o bem e para o mal, definem decisivamente a direção daquilo que é narrado pelos testemunhos; ou então a afetação moral do Lanzmann ex-combatente da resistência perante os polacos e a forma tendenciosa como é descrito o posicionamento polonês na altura da invasão alemã; e, neste caso, a utilização altamente controversa de imagens da Varsóvia dos anos 80 para fazer passar a ideia de que, fora do gueto, os polacos viviam em perfeita normalidade, e que isso é a marca indesmentível de um colaboracionismo generalizado (Cf. Salles, 2012). 
lógicas da imagem e as peculiaridades da sua receção pelo sujeito. A imagem fotográfica (a rejeição do arquivo por parte de Lanzmann inclui naturalmente o arquivo fílmico e fotográfico, sendo necessário compreender o caráter epistémico e fenomenológico do suporte fílmico na sua aceção mais ampla) possui aquilo que, por exemplo, Marianne Hirsch, designou como constituindo uma "força evidencial" que se encontra implicada na conexão material da fotografia com o objeto que esteve lá, perante a lente, num determinado tempo e espaço. Mas, ao mesmo tempo, como afirma Hirsch, a fotografia pode ser extremamente desapontante pela sua transiência e fugacidade, assinalando uma distância intransponível com respeito à realidade - a fotografia revela tanto da realidade, quanto aquilo que ela encobre, sendo essa a fenomenologia fundamental de um processo constitutivo e ontológico que a define como imagem (Hirsch, 2001: 14).

É por isso que, como assinala Marianne Hirsch, as imagens fazem mais do que representar a realidade ou providenciarem um mero acesso factual ao passado. Elas têm também a habilidade de transmitir, como escreve Hirsch, "uma experiência corpórea e afetiva pela evocação das emoções e das memórias sensíveis do próprio espectador. Elas afetam o espectador, falando a partir das sensações materiais, em vez de falarem de, ou representarem o passado" (Hirsch, 2001: 15). Era precisamente neste sentido que Marianne Hirsch era levada a integrar, logo no início do seu texto, duas passagens relativas a dois encontros traumáticos com as imagens do horror Nazi, tais como descritos, respetivamente, por Susan Sontag em On photography (1973), e por Alice Kaplan, em French lessons (1993):

Eram apenas fotografias - de um evento do qual eu mal tinha ouvido falar e em relação ao qual nada podia fazer, de um sofrimento que eu não conseguia imaginar e não podia atenuar. Quando olhei para essas fotografias, algo rompeu. Algum limite tinha sido atingido, e não apenas o do horror; eu sentime irrevogavelmente afligida, ferida, mas uma parte dos meus sentimentos começaram a comprimir-se; algo morreu, algo ainda chora (Susan Sontag).

A minha mãe tinha visto as fotografias para retirar aquelas que ela considerava serem demasiado chocantes, mas eu queria levá-las todas, especialmente as mais impressionantes... Eu acreditava que os meus amigos não tinham o direito de viver sem conhecerem estas fotografias, como podiam parecer tão felizes sendo tão ignorantes. Nenhum deles sabia o que eu sei, pensei. Detestava-os por isso (Alice Kaplan).

O encontro com as imagens de horror produz, nestes casos, exatamente o efeito oposto àquele que estaria implicado na consideração das imagens de arquivo do Holocauto como véus, como substitutos, como repetições compulsivas que bloqueariam o trauma através de um efeito de alienação especular. 
Elas não são, definitivamente, substitutos atrativos da falta (definição de $f e$ tishe), podendo antes surgir como imagens do próprio deslocamento (imagens que expressam uma espécie de real último onde falha toda a mediação, como viu Didi-Huberman a partir de Jacques Lacan) (Didi-Huberman, 2012: 108). Essa violentação provocada pela imagem leva o sujeito a descobrir e a confrontar os aspetos que preferiria manter ocultos, invisíveis e inimagináveis, numa experiência que pode ser equiparada ao trabalho doloroso do luto no seu significado psicanalítico.

\section{Pós-memória, trabalho de memória e fetichização narrativa}

Marianne Hirsch sublinharia assim o aspeto ético e intersubjetivo da relação imposta pela pós-memória: a experiência traumática do outro é inscrita na nossa própria experiência, uma vez que aquilo que somos depende da nossa existência cultural e da nossa resposta aos factos coletivos e sociais (Hirsch, 2001: 15). Como tal, esta (pós) memória, definida pelo seu caráter crítico e ativo, pode inclusivamente fazer intervir construções fabulatórias e narrativas que transportam a marca de uma exigência ética e política. Trata-se de uma forma de ritualização e de fabulação que não pode, naturalmente, ser confundida com a constituição de uma narrativa que, consciente ou inconscientemente, seria orientada pelo desejo de ocultação dos traços traumáticos do evento. Era neste sentido que Eric Santner viria a distinguir aquilo que, por um lado, ele designa como o fetichismo narrativo, e, do outro, o trabalho positivo do luto:

O trabalho de luto é um processo de elaboração e integração da realidade da perda ou do choque traumático pela sua recordação e repetição simbólica e dialógica doseada; é um processo de tradução, metaforização e figuração da perda, e, como Dominick LaCapra assinalou, pode incluir uma relação entre a linguagem e o silêncio que é de certo modo ritualizada. $\mathrm{O}$ fetichismo narrativo, pelo contrário, é o modo pelo qual a inabilidade ou a recusa do luto narrativiza os eventos traumáticos; é uma estratégia de evitação, na fantasia, da necessidade do luto pela simulação de uma condição de intocabilidade, tipicamente pela localização do espaço e da origem da perda num outro lugar. O fetichismo narrativo liberta o indivíduo do sofrimento de reconstituição da sua identidade sob condições pós-traumáticas; no fetichismo narrativo o pós é indefinidamente adiado. (Santner 1992: 144). ${ }^{2}$

2. As tentativas de reelaboração da identidade germânica que surgiram na década de 80 , no contexto da designada disputa histórica (Historikerstreit), por autores como Andreas Hillgruber, constitui um exemplo claro daquilo que Santner designa como uma tentativa de "reajustamento mnemónico" que ignora a necessidade do trabalho do luto (neste caso, a glorificação de episódios narrados de forma dramática por Hillgruber, como por exemplo aquele respeitante à defesa derradeira dos territórios situados a Leste pelas tropas alemãs, no período de colapso do Império, faz esquecer que esse ato heroico permitiu a continuação do funcionamento dos campos de morte e que o genocídio não pode ser apagado da memória da guerra) $(144 ; 148)$. Um 
Esta passagem é importante por sublinhar a ideia de que o trabalho de luto, considerado como exercício crítico da memória, implica processos de "tradução, metaforização e figuração". São, se quisermos, processos de encenação e de exposição narrativa que integram a perda, não podendo ser confundidos com as estratégias de evitação e de substituição definidoras do fetichismo narrativo. A utilização do filme no trabalho de construção histórica denuncia exemplarmente que a exposição narrativa não consiste apenas, como demonstrado exaustivamente por exemplo por Hayden White (White, 1992), em proposições factuais e objetivas, incluindo igualmente elementos poéticos e retóricos, intrigas, figuras de estilo e tipologias próprias que são integradas num trabalho fabulatório, convertendo os factos em histórias. Aliás, o facto pressupõe sempre uma relação entre o acontecimento e a forma como este é descrito, interpretado e exposto. $\mathrm{O}$ facto não designa uma instância estável e definitiva que seria passível de ser explicada e transmitida na sua identidade plena. O conhecimento histórico é incompatível com uma forma fechada e definitiva; ele implica a revisão e a produção de novas perspetivas dependentes das condições do presente (White, 1992: 311-12). Desta forma, a narrativa cria os factos. Ela não se limita a representá-los, mas participa na sua própria constituição.

É nesta perspetiva que a vertente crítica da estética pós-moderna do filme (encontrada em autores como J.-L.Godard, Alain Resnais, Harun Farocki, Chris Marker, ou Hans-Jürgen Syberberg) incorpora uma reflexão importante sobre os próprios limites da representação. Ela apresenta esses limites não como uma linha negativa que não pode ser ultrapassada, mas sim como um espaço de produção de múltiplas alternativas. Ela liberta-nos da ideia de que o realismo na representação pode ser absoluto. Mais exatamente, afirma a inadequação de qualquer tipo de representação puramente realista de um acontecimento como o Holocausto, sem que isso implique uma espectacularização ou uma dramatização abusiva da dimensão perturbadora, inconcebível e problemática do evento. Este deverá emergir a partir de uma representação "extracanónica",

outro caso apresentado por Santner é o do filme de Edgar Reitz intitulado Heimat, transmitido pela televisão alemã em 1984 e coroado de êxito. Heimat aborda o período Nazi por via de uma substituição do tema inalienável do extermínio dos Judeus pela dramatização do sofrimento do povo alemão separado da sua pátria e da sua tradição no período do pós-guerra, fornecendo uma imagem fetiche de vitimização da nação agressora (149). Consideramos que é no entanto necessário não diminuir o sofrimento daqueles que foram perseguidos e experimentaram a vingança por parte dos vencedores da guerra: o filme Tondues en 44, de 2007, de Jean-Pierre Carlon, por exemplo, documenta os castigos ignominiosos a que foram submetidas as mulheres francesas que se envolveram afetivamente com militares alemães na altura da ocupação Nazi. Essa é uma temática abordada igualmente por Alain Resnais, recorde-se, em Hiroshima mon amour de1959. Finalmente, filmes como A Lista de Schindler (1993) podem ser considerados, apesar da sua vertente humanista, narrativas orientadas por princípios estéticos e dramatúrgicos que se revelam inadequados a um exercício de memória crítica que visa o acontecimento não só na sua dimensão inconcebível e impensável, como também na sua complexidade cultural e identitária. 
"suspensa entre a história e a memória, suspensa também entre a literatura e o documentário, cujo objeto é consistentemente a resposta diária ao terror [...]" (Hartman, 1992: 324).

É pois neste ponto que gostaríamos de reintroduzir a questão inerente à utilização da imagem (de) arquivo na representação do acontecimento do Holocausto. Tratar-se-á, mais exatamente, de pensar o problema que concerne aos limites e às potencialidades do filme na sua relação com a montagem e a respetiva convergência com o ato da memória e do pensamento. Neste ponto, o projeto Histoire( $s)$ du cinéma, de Jean-Luc Godard, surge como um ponto de análise privilegiado, até porque ele é sustentado numa conceção da imagem de arquivo, e, consequentemente, da montagem cinematográfica, diametralmente oposta àquela advogada por Claude Lanzmann.

\section{Pluralismo histórico e escrita paratática: as Histoire(s) de Godard}

As críticas dirigidas ao projeto Histoire( $s)$ du cinéma, de J.-L-Godard (1998), baseiam-se em dois argumentos principais. O primeiro concerne à ideia de que a montagem é gratuita e aleatória, que ela se limita a misturar tudo com tudo, não respeitando a singularidade histórica dos acontecimentos. Esta crítica reflete um ceticismo geral relativamente àquilo que determinadas correntes teóricas definem como o relativismo da estética pós-moderna. $\mathrm{Na}$ sua análise ao projeto de Hans-Jürgen Syberberg, Hitler: Um filme da Alemanha (1977), - filme que partilha com as Histoire(s) algumas aproximações metodológicas e relações estéticas importantes, - Anton Kaes afirmaria, a título exemplificativo, que a estética pós-moderna do filme de Syberberg opera uma cisão dos eventos e das personagens do passado com os seus contextos originais. Eles são convertidos em elementos citáveis e combinados numa estrutura orientada por princípios estéticos, independentemente de preocupações históricas e de rigor analítico (Kaes, 1992: 211). Para Anton Kaes, a facilidade com que Syberberg usa o passado como material que pode ser citado reflete uma conceção negativa do fim da história. A história desemboca num impasse, fazendo com que o presente se eternize numa referência infindável ao passado (Kaes, 1992: 118). Kaes expressa, desta forma, os principais critérios que estão na base da crítica ao relativismo da estética pós-moderna. O segundo argumento em que se baseia a condenação das Histoire( $(s)$ deriva desta conceção crítica do pluralismo histórico. Defende-se, neste caso, que a estratégia de citação de elementos pertencentes a diferentes períodos, contextos e proveniências, redunda num exercício de estilo que faz aparecer a imagem como símbolo de uma ostentação icónica ligada ao caráter ilusório, substitutivo e fantasista da figuração. Sustenta-se, inclusivamente, que, no caso das 
Histoire(s), essa operação de ostentação icónica tem como efeito a elevação da imagem ao estatuto de objeto de crença e de relíquia, numa associação entre a crença religiosa e a fetichização da imagem, hipoteticamente corporizada na fórmula godardiana de que a imagem surgirá no tempo da sua ressureição (Didi-Huberman, 2012, 162).

Michael Witt havia já demonstrado que a ampla referência de Godard ao cristianismo nas Histoire( $(s)$ adquire uma função alegórica e, sobretudo, histórica (Witt, 2013, 132). O aforismo pauliniano, adotado por Godard, de que $a$ imagem virá no tempo da sua ressureição, deve ser perspetivado ao nível de uma conceção ampla de montagem, compreendida como processo capaz de produzir significações novas a partir da combinação entre imagens que são reconfiguradas à luz do seu embate e confronto com o presente: Como escrevia Godard, "A base é sempre dois; apresentar inicialmente sempre duas imagens em vez de uma é aquilo a que chamo imagem, esta imagem feita de dois [...]" (Godard, 2000. Cit. Didi-Huberman, 2012, 162). A montagem providencia uma nova capacidade de reflexão, de imaginação e de criação do conhecimento histórico. Em Godard, a montagem é o que faz ver aquilo que se gera nos interstícios das imagens, mas também nos intervalos criados pelas "colisões desmultiplicadas" entre as palavras e as imagens citadas (Didi-Huberman, 2012, 177). A montagem articula as fronteiras do texto e da imagem, integrando formas de pensamento interrogativas e padrões de inteligibilidade que pervertem as associações convencionadas e a lógica do contínuo explicativo. Por isso Godard afirmava que:

A imagem entra no texto, e o texto, num dado momento, acaba por surgir das imagens. Já não há uma simples relação de ilustração. Isso permite-lhe exercer a sua capacidade de pensar, de refletir, de imaginar e de criar. [...] A certa altura, isso interpelou-me como uma imagem, o facto de serem duas palavras que [são] aproximadas. (Godard, 2000. Cit. Didi-Huberman, 2012, 162).

Por isso Raymond Bellour podia referir-se a um "poder material das palavras" que devêm "um equivalente da imagem, uma parte, uma camada, um nível do que compõe uma imagem" (Bellour, 1999: 126). Godard transforma as palavras e os fragmentos discursivos extraídos dos livros, dos discursos e dos filmes citados, e faz entrar a palavra no circuito do documentário, cujo material visual, em Histoire( $s$ ) du cinéma, é igualmente submetido a um processo de extração, citação e recontextualização dos fragmentos. Assim, segundo Raymond Bellour,

Tal implica igualmente a possibilidade de tratar a escrita como imagem [e] o ecrã como uma página. E assim de subtrair a escrita à sua legibilidade própria para fazer dela o objeto de um visível-legível que garante a sua plasticidade 
in vivo no tempo da inscrição e do desdobramento (é isto que, entre outras coisas, se atinge plenamente em Histoire(s) du cinéma). (Bellour, 1999: 126).

Rancière avançaria, da sua parte, no sentido da identificação, a partir das Histoire(s), de uma "potência frásica", relacionada com uma espécie de grande parataxe que desfaz o esquema de causalidades ideais e as normas habitualmente reguladoras da produção do inteligível e do sensível (Rancière, 2011: 67). No caso de Godard, os signos apresentados são, segundo Rancière, "elementos visuais agenciados na forma do discurso", envolvendo uma "sintaxe paratática" que pode receber o nome de montagem, desde que, como temos visto, se alargue a noção para lá do seu significado mais restrito e especializado (Rancière, 2011: 67; 59).

Veja-se a sequência final do episódio 1A das Histoire(s). Godard combina imagens de arquivo de um filme de $16 \mathrm{~mm}$ Kodachrome dos campos de morte, registadas por George Stevens e mostrando corpos empilhados e rostos cadavéricos (numa analogia brutal com os rostos representados nas gravuras de Goya, inseridas anteriormente), com uma cena onde reconhecemos Elisabeth Taylor em fato de banho, segurando sobre si o amante, Montgomery Cift. Aparentemente incompreensível, esta relação é, na verdade, fundamentada pela voz off: George Stevens é o autor de ambos os fragmentos apresentados (o de Elisabeth Taylor, no filme Um lugar ao sol (1951), e o do registo do campo de morte). É o realizador que só pôde voltar a Hollywood e filmar a cena de felicidade radiante e de pacificação, porque entrou nos campos com os Aliados, e porque decidiu, em 1945, utilizar o primeiro filme a cores em $16 \mathrm{~mm}$ para testemunhar a realidade das atrocidades cometidas. ${ }^{3}$

Este exemplo mostra que, em Godard, a montagem não impõe um todo. Ela é antes um modo de fragmentação que fornece uma nova independência à imagem e ao ato da palavra, implicando a transformação das duas componentes ao nível de passagens e de aproximações que expressam aquilo que não se pode ver. É isto que une os projetos aparentemente complementares de Claude Lanzmann e de Jean-Luc Godard, recaindo ambos sobre a ideia de que o acontecimento do extermínio da Segunda Guerra obriga a um repensar mais amplo da nossa relação com a imagem.

3. Sobre esta relação Godard diz: "Há uma coisa que sempre me tocou muito num cineasta de quem gosto mais ou menos, George Stevens. Em Um lugar ao sol, encontrei um sentimento profundo de felicidade que raramente encontrei noutros filmes, mesmo em filmes melhores. Um sentimento de felicidade laico, simples, percetível, momentâneo, em Elisabeth Taylor. E quando soube que Stevens tinha filmado os campo de concentração e que, então, a Kodak lhe tinha confiado os primeiros filmes a cores de dezasseis milímetros, não encontrei outra explicação para que em seguida ele pudesse ter feito este grande plano de Elisabeth Taylor irradiando esta espécie de felicidade sombria”. Godard, J.-L. (1998b) Jean-Luc Godard par Jean-Luc Godard. Paris: Cahiers du Cinéma, p.172. 
Mas a diferença entre ambos observa-se, desde logo, a um nível formal. Como viu Didi-Huberman, onde Lanzmann faz uso de uma forma de "montagem centrípeta", baseada no ritmo lento e no tempo dilatado que acolhe os discursos das testemunhas, Godard opõe uma "montagem centrífuga", baseada na proliferação dos centros e na fusão entre imagens e palavras que são citadas, criadas e recontextualizadas a partir de um mosaico de referências múltiplas (Didi-Huberman, 2012: 161). Essa espécie de mosaico hieroglífico sugere, além do mais, a interdependência do Holocausto com outros fenómenos históricos, a começar pela história das estórias do próprio cinema. Em segundo lugar, a disparidade teórica entre Claude Lanzmann e J.-L.Godard aprofundase quando se examina o posicionamento dos dois realizadores relativamente ao valor da imagem e dos arquivos na representação do Holocausto. Onde em Lanzmann a imagem é inadequada à expressão da reserva do acontecimento, adquirindo quanto muito um valor de prova documental, em Godard a imagem possui um poder de evocação construído no interior de um trabalho laborioso de montagem entre as palavras e as imagens. Para Godard, o impacto afetivo e sensorial da imagem faz com que esta apareça como uma espécie de vidência, suscetível de transmitir aquilo que não pode ser mostrado nem dito através das formas de encadeamento explicativas do texto, ou das soluções dramatúrgicas do cinema. É sobretudo esta diferença de perspetiva relativamente aos poderes e funções da imagem que cava uma distância inconciliável entre as cinematografias de Lanzmann e de Godard.

Neste ponto, porém, é necessário sublinhar que a afirmação das potencialidades evocativas e poéticas da imagem, por parte de Godard, vai a par de uma aguda compreensão do seu valor indicial e testemunhal. É que, apesar de em Godard a imagem constituir um traço, cuja verdade não é senão perseguida ao nível de um exercício de montagem sempre incompleto e parcial constituindo, se quisermos, uma espécie de exercício de verdade que capta a significação da imagem apenas ao nível dos seus efeitos posicionais, reencadeamentos e diferenças - ao mesmo tempo, ele não partilha da posição mantida por uma certa corrente acrítica pós-moderna, caracterizada pela desqualificação do poder testemunhal e referencial da imagem e do próprio arquivo.

É esta conceção, contraditória apenas na sua aparência, que se encontra firmada na formulação godardiana de que "mesmo deteriorado um simples retângulo de trinta e cinco milímetros salva a honra de todo o real" (Godard, 1998a: 88). Esta fórmula deve ser compreendida ao nível da teorização godardiana da função documental do suporte fílmico, que atua como uma impressão por contacto material do objeto. O suporte fílmico comporta pois a ideia de um contacto direto com o mundo; constitui um lastro de realidade que transmite a 
experiência do acontecimento através de vestígios brutos. Dito de outro modo, a imagem preserva um fragmento (um retângulo) da realidade: parafraseando Godard, não uma imagem verdadeira, mas somente uma imagem.

Assim, se o retângulo de $35 \mathrm{~mm}$ implica uma ética é porque, desde logo, ele salva o acontecimento do seu desaparecimento. Mais, esse retângulo - qual escudo de Perseu que derrota Górgona por via do reflexo da imagem redirecionada - permite defrontar o horror do real, levando o sujeito a incorporar essa possibilidade nos seus processos cognitivos e mnésicos. A imagem não salva os grandes valores, mas redime um saber e recita a memória do tempo histórico, como viu Didi-Huberman. ${ }^{4}$ E se, nas Histoire(s), Godard faz cruzar a fórmula textual do retângulo de trinta e cinco milímetros com imagens de arquivo de corpos pulverizados, vítimas da Guerra, é porque ele pretende demonstrar que aquilo que as imagens salvam, ou redimem, é justamente o horror da sua invisibilidade e esquecimento. Neste sentido, elas não constituem véus, formas pacificadoras, mas assumem-se, pelo contrário, como veículos de conhecimento daquilo que se pretenderia manter ocultado e longe de nós. Prescindir delas ou recusar olhar o seu horror equivaleria, como assinalado por Didi-Huberman, a fechar os olhos, a denegar a sua existência e compreensão, recalcando o acontecimento ao nível de uma espécie de amnésia histórica era este, justamente, o problema colocado por Harun Farocki em The inextinguishable fire (1969), que recai sobre a problemática da violência das imagens das vítimas de Hiroshima.

Existe, a este primeiro nível, um poder de testemunho da imagem que não pode ser excluído. Ele obriga o espectador a defrontar o horror e o excesso, que irrompe brutalmente pela imagem sob uma forma do visível que desregula uma certa ordenação entre aquilo que é visível e aquilo que é invisível, entre o que é da ordem do saber e do não-saber. Mas esse poder de testemunho observa igualmente modos de sobrevivência e de repetição que se entrelaçam no tecido da memória como construção, como trabalho do tempo na imagem (Didi-Huberman, 2012: 209-10). É esse trabalho sobre a imagem e o próprio arquivo enquanto instâncias sempre parcelares e dispersivas (e aqui o sentido metafórico da deterioração evocada por Godrad), que, finalmente, cria pontos de ligação ao presente e à particularidade da experiência vivida, experiência que é também, no seu sentido mais profundamente nietzschiano, uma vivência histórica das imagens.

4. Como observa Didi-Huberman, a metáfora do escudo de Perseu é utilizada por Siegfried Kracauer na sua defesa da dimensão redentora da imagem cinematográfica, comparando o ecrã de cinema ao escudo refletor (Didi-Huberman, 2012: 22-223); (Cf. Kracauer, 1969: 305-06). 


\section{O cinema, uma forma que pensa e que é feita para pensar}

A componente citacional de Histoire( $s$ ) du cinéma, trabalhada por via da montagem diferencial de elementos sonoros e visuais, vai ao encontro, de forma consciente ou não, da ideia de que o inconcebível do sofrimento humano não é exclusivo de um povo, ou melhor, não é exclusivo de um acontecimento que teve lugar num tempo e num espaço passível de ser cortado de um antes e de um depois, mesmo que aquele possua características absolutamente singulares. Também aqui, Godard adota um posicionamento distinto do de Claude Lanzmann, que afirmava que o Holocausto se refere a um tempo e a um espaço únicos, a algo que nunca havia acontecido e que não voltará jamais a acontecer. Lanzmann colava-se, dessa forma, a uma perspetiva que tende a afirmar para o Holocausto a exclusividade do paroxismo da dor e do sofrimento humanos. Porém, como defendia Peter Haidu, é a comparação que permite aferir da unicidade do evento histórico: se negar a especificidade do extermínio Nazi é uma "mistificação da história", declarar que não há paralelos e que o fenómeno queda inexplicável também o é (Haidu, 1992: 296).

Convém lembrar, neste contexto, que Histoire( $s$ ) du cinéma não é, ao contrário do que acontece com o documentário de Lanzmann, um filme sobre o extermínio. As Histoire( $s$ ) mapeiam antes a influência desse acontecimento na forma como perspetivamos a imagem nos nossos dias, assim como as implicações para as possibilidades de futuro da prática e conceptualização cinematográfica. Neste sentido, parece-nos que uma das grandes teses de Godard, em Histoire(s,) du cinéma, concerne à tentativa de relacionamento do Holocausto com o contexto politico, social e mediático do presente, preocupação que é refletida, por exemplo, na frequente referência ao massacre de Srebrenica na ex-Jugoslávia, em 1995. O posicionamento teórico adotado por Godard parece assim responder à exigência, formulada por um autor como Yehuda Bauer, de que o Holocausto deve ser tratado como uma coisa do presente e não do passado. O facto de o Holocausto ter acontecido no nosso século e na nossa cultura, o facto de ser uma ocorrência atual e não o produto de uma qualquer intervenção de tipo sobrenatural, demonstra, como assinalado por Bauer, que o Nazismo constitui uma "possibilidade lógica resultante da história Europeia", embora revelada nos seus traços mais hediondos e macabros. ${ }^{5}$

Esta exigência que concerne a uma reflexão crítica de índole política e social era já convocada por Alain Resnais e Jean Cayrol em 1955. Um alerta pungente marca o fim de Nuit et brouillard. Nós fingimos, é dito pelo comentário em off, que tudo aconteceu apenas uma vez, num só tempo e num

5. Baseamo-nos aqui no estudo de Peter Haidu sobre o pensamento de Yehuda Bauer, The Holocaust in historical perspetive, 1978, p.36. Cit. Haidu, 1992: 292. 
só país. Pretendemos crer e fazer crer que o "monstro contraccionário" recua num passado cada vez mais longínquo, como se estivéssemos salvos dessa peste, fechando os olhos ao sofrimento e às injustiças que nos rodeiam. Mas questiona-se:

[...] quem de nós vigia, dessa estranha torre de controlo, para nos advertir da chegada dos novos algozes? São os seus rostos verdadeiramente diferentes dos nossos? Em qualquer parte, entre nós, continuam a existir afortunados kapos, oficiais reestabelecidos, informadores anónimos. Há sempre aqueles que se recusam a acreditar, ou acreditam apenas de longe a longe (Cayrol, 1955).

Talvez porque haja sempre quem se recuse a acreditar e a olhar, ou quem acredite e olhe, mas faça submergir o inconcebível no lamaçal do inimaginável e da amnésia histórica, que Alain Resnais decide fazer uso das mais violentas imagens de arquivo que registaram a experiência dos campos. A discussão sobre o Nazismo persiste como um tema do presente pois ele possibilita uma compreensão renovada das condições de existência do indivíduo contemporâneo e das relações de poder que ele integra; persiste como tema do presente uma vez que as bases e pressupostos teóricos dos modelos de organização económica, social e política, consolidados nas sociedades capitalistas do fim do século XIX, e início do século XX, continuam a caracterizar as grandes configurações das sociedades atuais.

É neste sentido que devemos compreender um dos momentos mais polémicos de Histoire( $s$ ) du cinéma, no qual Godard combina, em 4A, excertos de um filme pornográfico com uma imagem dos campos, na qual vemos um cadáver esquelético a ser levantado para ser empilhado juntamente com os corpos de outras vítimas. Numa primeira análise, esta justaposição é orientada pela alusão às singularidades históricas do acontecimento. Georges Didi-Huberman argumentaria que Godard estava a mostrar as coisas no seu aspeto mais problemático, relembrando que elas existiam já juntas: nos campos, o mesmo adjetivo, sonder (especial), designava a morte (sonderbehandlung, isto é, ações especiais de gaseamento), mas também a coação ao sexo e à prostituição (sonderbau, ou bordel). ${ }^{6}$

Mas a articulação ativada por Godard implica também uma referência, e até um apelo, ao facto das práticas da imagem deverem integrar configurações de resistência que lutam contra as formas opressivas da indústria audiovisual, - corporizadas de modo particular nas formas televisivas e mediáticas, - lembrando que o cinema possui uma responsabilidade ética que é conferida pela

6. Por isso Godard referia que "[...] não se trata de pôr tudo no mesmo saco; as coisas são apresentadas em conjunto; a conclusão não está imediatamente dada. [...] Elas existiram juntas; recorda-se pois que elas existiram juntas" (Godard 2000. Didi-Huberman, G. (2012) Imagens apesar de tudo. Lisboa: KKYM, p.192. 
sua componente testemunhal. A crítica violenta de Godard relativamente ao impacto da televisão relaciona-se, precisamente, com a denúncia das formas de reificação a que o sujeito, e o próprio pensamento, são submetidos pela mercantilização da imagem e dos corpos. ${ }^{7}$ É pois neste momento benjaminiano de perigo que Godard apela às possibilidades futuras do cinema, as quais devem integrar uma dimensão ética e política incompatível com as formas espectacularizadas do entretenimento. Mas, ao mesmo tempo, e por isso mesmo, a denúncia ativada pela imagem não deve ser meramente uma figuração da violência e do sofrimento, mesmo quando aquilo que está em causa é a responsabilidade ética associada à sua função documental. A imagem deve converter-se, ela própria, numa instância de violentação do pensamento e do visível: é essa dilaceração que a imagem cinematográfica deve causar. Finalmente, parece ser esse o sentido último do redentório em Godard.

Não é pois por acaso que Godard afirma que a montagem empresta ao cinema a qualidade de se converter numa forma que pensa, e que é feita para pensar. Mas esse pensamento só é válido se violentar o pensamento e aquele que pensa (Godard, 1998a: 45). É por isso que Godard exorta a um pensamento que "devenha aquilo que é na realidade: perigoso para o pensador e transformador do real" (Godard, 1998a: 41). Um pensamento que se abandona aos seus ritmos e esquemas padronizados é um pensamento que se proletariza, é um pensamento que se deixa dominar pelo culto da opinião, pela espectacularização e pelos consensos mediáticos, assim como pelas leis e valores canonizados, impedindo que ele se imponha na sua verdadeira força e potência. Isto é, que ele se imponha como um ato de criação, envolvendo até a condição pragmática do pensamento que incita o homem a pensar com as próprias mãos (Godard, 1998a: 45). É esta a dimensão ética e política do pensamento, do ato de pensar, que se revela inseparável de uma prática visual equiparável a uma escrita por imagens:

Todo o ato criador, escreve Godard, contém uma ameaça / real / para o homem que ousa / é por essa via que uma obra / toca o espectador ou o leitor / se o pensamento se recusa a pesar / a violentar / ele submete-se infrutiferamente / a todas as brutalidades / que a sua ausência liberou. (Godard, 1998a: 41).

Nas Histoire( $(s)$, este texto sobrepõe-se, não por acaso, à montagem acima mencionada entre morte e pornografia. O texto não se limita a descrever as imagens; ao contrário, ele redimensiona as trajetórias de sentido possibilitadas

7. Como observado por Natalia Tacceta, em Godard a televisão liga-se à espectacularização da guerra e da morte, numa lógica de consumo alienante que caracteriza a cultura ocidental contemporânea. Em Histoire( $s$ ) du cinéma esta tese é por exemplo explorada na série onde a legenda RAI (Radiotelevisão Italiana) é sobreposta a um quadro de Henri Rousseau intitulado A Guerra (1894), convertendo-se depois em REICH 3, ecoando sob o fundo de uma marcha Nazi (Tacceta, 2015: 242). 
pela montagem das imagens, demonstrando que aquilo que está em causa é a reflexão mais ampla sobre a relação do cinema - tomado como ato de criação - e a vida quotidiana, isto é, os processos que definem as possibilidades de ação, de pensamento e de expressão do indivíduo e do coletivo num dado momento cultural. É neste ponto, que define a feliz convergência entre a paratática do filme e a ação do pensamento, que se torna possível identificar uma componente fortemente deleuziana na prática visual de Godard. Em Deleuze, o pensamento constitui algo que se $f a z$ e não algo que é: implica interpretar, selecionar e analisar, mas também experimentar e criar. Deste modo, ele pode emergir como ato de criação e de experimentação do novo. Donde J.-L.Godard afirmar que o pensamento se faz com as mãos, aludindo ao gesto da montagem cinematográfica como um ato de combinação que pressupõe relações, metáforas, analogias e passagens entre as imagens visuais e sonoras. Isto é, toda uma atividade pensante e sensorial, na qual a imagem habita e reconfigura a superfície cinematográfica, introduzindo curvaturas e relevos variáveis no decurso da sua própria construção e experimentação. ${ }^{8}$

$\mathrm{O}$ cinema de Godard torna-se, em boa verdade, naquilo que o pensamento filosófico deveria ser para Deleuze: uma misosofia, espaço de incoerências, fissuras, lapsos, gaguejos, erros e intervalos que nascem da experimentação e da errância que é afeta a qualquer ato de criação, furando os modelos de organização de um pensamento aprisionado que sonha a unidade e o consenso. Por isso Deleuze seria levado a questionar: "O que é um pensamento que não faz mal a ninguém, nem aos que pensam nem aos outros a quem se dirige?" (Deleuze, 1994: 136). Ou seja: o que é um pensamento que se limita a veicular os valores já dados e concertados? A filosofia deve pois conter uma "violência original infligida ao pensamento" (Deleuze, 1994: 139), deve acordar o pensamento do seu estupor e conivência com o instituído. Deve surgir, segundo Deleuze, da contingência de um encontro que força o pensamento como uma paixão do pensar. Filosofia e Arte cinematográfica aproximam-se neste relançar dos possíveis, abrindo buracos nas formas consensualizadas do pensamento e dos domínios sensíveis institucionalizados (Fontes, 2007: 4).

Ainda que necessariamente sucinta, esta contextualização da obra filosófica de Deleuze revela-se crucial para compreender um dos aspetos mais significativos da imagem-tempo no seu conflito com a imagem-movimento. A

8. Neste sentido, em Deleuze o ecrã cinematográfico converte-se numa gigantesca superfície cerebral e mnésica: "O mundo tornou-se memória, cérebro, sobreposição de idades ou de lóbulos, mas o próprio cérebro tornou-se consciência, continuação das idades, criação ou aumento dos lóbulos sempre novos, recriação da matéria à maneira do estireno. O próprio ecrã é a membrana cerebral onde se confrontam imediata, diretamente o passado e o futuro, o interior e o exterior, sem distância atribuível, independentemente de qualquer ponto fixo [...] A imagem já não tem como características primeiras o espaço e o movimento, mas a topologia e o tempo." Deleuze, G. (2006) A imagem-tempo. Lisboa: Assírio \& Alvim, p.164. 
imagem-movimento como automatismo do movimento e máquina estética e filosófica é suscetível de produzir, ainda hoje, um sujeito pensante que pensa sob o efeito do choque das imagens, mas também uma espécie de autómato psicológico, como via Gilles Deleuze (Deleuze, 2006: 341-42), despossuído do seu próprio pensamento e submetido à alienação imposta pela força ideológica das imagens, convertidas em mera informação e espetáculo. Ao introduzir uma nova desordem a partir das imagens e dos discursos anteriormente estabilizados, o cinema da imagem-tempo abre um espaço de pensamento e de reflexão crítica. Por essa via, e surgindo como meio que encerra a vontade original da arte, o cinema pode restituir a nossa ligação ao mundo e aos acontecimentos através de práticas que ultrapassam a informação, avançando modalidades de "fabulação criativa", como dizia Deleuze, capazes de voltar a imagem do avesso e de "[criarem] o mito em vez de lhe tirar o benefício ou a exploração" (Deleuze, 2006: 342).

Ora, em Godard, a imagem captada nos seus efeitos de montagem inscreve, justamente, um exercício de construção fabulatória que restitui o acontecimento através de novas leituras. Em Godard, a montagem avança pois por vias originais, reinventa e recria o sentido histórico das imagens, produz cortes e extraterritorialidades que fazem passar o que antes permanecia enterrado, intransmissível, ou, simplesmente, atolado no lamaçal informativo. E, tal como em Deleuze, também em Godard a restituição dessa ligação do cinema à vida é objeto de crença. Mas agora a crença não se refere a um outro mundo transcendental ou mitificado. A crença é a deste mundo, é a ela que o cinema deve referir-se, apelando a uma espécie de transcendental histórico que estabelece vias originais para o pensamento, num face-a-face do homem com o impensável e o intolerável do acontecimento.

\section{Referências bibliográficas}

Adorno, T. (2009). Dialética negativa (trad. M. A. Casanova). Rio de Janeiro: Zahar.

Bellour, R. (1999). L'entre images 2. Mots, Images. Paris: P.O.L.

Deleuze, G. (2006). A imagem-tempo. Lisboa: Assírio \& Alvim.

Deleuze, G. (2004). Bergson's conception of difference. Desert Islands and other texts (pp. 22-31). Massachusetts, Cambridge, London: MIT Press

Didi-Huberman, G. (2012). Imagens apesar de tudo. Lisboa: KKYM.

Fontes Filho, O. (2007). Francis Bacon sob o olhar de Gilles Deleuze: a imagem como intensidade. Viso: Cadernos de Estética Aplicada, 3. Rio de Janeiro. 
Godard, J.-L. (1998 a). Histoire(s) du cinéma. Paris: Gallimard-Gaumont.

Godard, J.-L. (1998 b). Jean-Luc Godard par Jean-Luc Godard. Paris: Cahiers du Cinéma.

Haidu, P. (1992). The dialectics of unspeakability: language, silence, and the narratives of desubjectification. In S. Friedlander (ed.), Probing the limits of representation (pp. 277-299). Cambridge, Massachusetts, London: Harvard University Press.

Hartman, G. H. (1992). The book of destruction. In S. Friedlander (ed.), Probing the limits of representation (pp. 318-336). Cambridge, Massachusetts, London: Harvard University Press.

Hirsch, M. (2001). Surviving images: Holocaust photographs and the work of postmemory. The Yale Journal of Criticism, 14 (1): 5-37. Baltimore.

Kaes, A. (1992). Holocaust and the end of history: postmodern historiography in cinema. In S. Friedlander (ed.), Probing the limits of representation (pp.206-222). Cambridge, Massachusetts, London: Harvard University Press.

Kracauer, S. (1960). Theory of film. The redemption of physical reality. Intr. Miriam Bratu Hansen. New Jersey: Princeton University Press.

Lanzmann, C. (s.d.). Le Monument contre l'archive. Entrevista com Daniel Bougnoux et al., Cahiers de Médiologie, (11) : 271-279. Paris. Disponível em : http://mediologie.org/cahiers-de-mediologie/11_transmettre/lan zmann.pdf

Rancière, J. (2011). O destino das imagens. Lisboa: Orfeu Negro.

Rodowick, D. N. (1997). Gilles Deleuze's time-machine. Durham and London: Duke University Press.

Santner, E. L. (1992). History beyond the pleasure principle: some thoughts on the representation of trauma. In S. Friedlander (ed.), Probing the limits of representation (pp. 143-154). Cambridge, Massachusetts, London: Harvard University Press.

Salles, J. M. (2012). Debate no IMS-RJ entre João Moreira Salles, Eduardo Coutinho e Eduardo Escorel. Disponível em: www.youtube.com/watch?v $=87 \mathrm{ZloNfiwSU}$

Tacceta, N. (2015). Histoire(s) du cinéma: el archivo del siglo. Aniki. Revista Portuguesa da Imagem em Movimento, 2 (2): 224-250.

White, H. (1992). Historical emplotment and the problem of truth. In S. Friedlander (ed.), Probing the limits of representation (pp.37-53). Cambridge, Massachusetts, London: Harvard University Press. 
Witt, M. (2013). Jean-Luc Godard, cinema historian. Bloomington and Indianapolis: Indiana University Press.

\section{Filmografia}

Nuit et brouillard (1955), de Alain Resnais.

Hiroshima, mon amour (1959), de Alain Resnais.

Le chagrin et la pitié (1969), de Marcel Ophuls.

Hitler: um filme da Alemanha (1977), de Hans-Jürgen Syberberg.

Shoah (1985), de Claude Lanzmann.

Histoire(s) du Cinéma (1998), de Jean-Luc Godard.

Tondues en 44 (2007), de Jean-Pierre Carlon. 